\title{
EL MODELO DE DERECHO DE PARTICIPACIÓN, LA PROTECCIÓN EFICAZ EN MATERIA DE SEGURIDAD Y SALUD EN EL TRABAJO Y SUS VÍAS DE REPARACIÓN: LA CULTURA DE LA PARTICIPACIÓN Y LA CULTURA DE LA PREVENCIÓN EN CLAVE DE RESPONSABILIDAD
}

The model of right of participation, the effective protection in matters of security and health in the job and its ways of reparation: the culture of the participation and the culture in the prevention in terms of responsibility

\section{Pompeyo Gabriel Ortega Lozano*}

Universidad de Granada, Espańa

\section{RESUMEN}

Es el empresario el sujeto obligado a garantizar la seguridad y la salud de los trabajadores a su servicio en todos los aspectos relacionados con el trabajo. Partiendo de esta afirmación, en este texto, por un lado, nos referimos al derecho de participación de los trabajadores y, por otro, la que en la práctica parece ser la cultura de prevención más eficiente: la responsabilidad administrativa, penal, civil y de Seguridad Social. Todo lo anterior, en plena vinculación con la Ley de Prevención de Riesgos Laborales.

Palabras clave: prevención, cultura, participación, consulta, responsabilidad.

\section{ABSTRACT}

The employer is the person who is compelled to guarantee the security and health of his/her employees in all respects related to the job. On the basis of this statement, in this text, on one hand, we refer to the right of participation of employees and, on the other hand, we refer to the culture of the prevention that seems to be the most efficient in practice: the administrative, criminal, civil and Social Security responsibility. All the above, in full link to the Law of Labour Risk Prevention.

Keywords: prevention, culture, participation, consultation, responsibility.

\footnotetext{
* Correspondencia a: Pompeyo Gabriel Ortega Lozano. C/Gran Vía de Colón, núm. 42, 4. ${ }^{\circ}$ B, Granada (Andalucia), España. - portega@ugr.es - https://orcid.org/0000-0001-9880-4231

Cómo citar: Ortega Lozano, Pompeyo Gabriel. (2020). «El modelo de derecho de participación, la protección eficaz en materia de seguridad y salud en el trabajo y sus vías de reparación: la cultura de la participación y la cultura de la prevención en clave de responsabilidad»; Lan Harremanak, 44, 184-217. (https://doi.org/10.1387/lan-harremanak.22160).

Recibido: 20 octubre, 2020; aceptado: 22 noviembre, 2020.

ISSN 1575-7048 - eISSN 2444-5819 / @ 2020 UPV/EHU
} 


\section{Negociación colectiva, derecho de participación y responsabilidad en la prevención de riesgos laborales}

La propia Ley de Prevención de Riesgos Laborales (en adelante, la Ley o LPRL) se refiere, de forma detallada, a los derechos de consulta y participación de los trabajadores en aquellas cuestiones que pudieran afectar a la seguridad y a la salud en el trabajo. Partiendo del propio sistema vigente en nuestro país, la citada Ley viene a atribuir la facultad de los derechos de participación a los denominados «Delegados de Prevención", elegidos por y entre los representantes del personal en el ámbito de los respectivos órganos de representación. Se atribuye así el ejercicio de las funciones especializadas en materia de prevención de riesgos en el trabajo, otorgándose (para dicha finalidad) competencias, facultades y garantías necesarias para el correcto desarrollo de esta negociación. Junto a los Delegados de Prevención, localizamos también el denominado Comité de Seguridad y Salud, continuando así la experiencia de actuación de una figura arraigada y tradicional de nuestro ordenamiento laboral, configurándose como aquel órgano de encuentro y participación entre los representantes y el empresario para el desarrollo de una participación equilibrada en materia de prevención de riesgos. Todo lo anterior, sin perjuicio de las posibilidades que otorga la propia Ley a la negociación colectiva para articular de manera diferente los instrumentos de participación de los trabajadores, incluso desde el establecimiento de ámbitos de actuación distintos a los propios del centro de trabajo, recogiendo con ello diferentes experiencias positivas de regulación convencional cuya vigencia, plenamente compatible con los objetivos de la LPRL, se salvaguarda a través de la disposición transitoria primera referida a la aplicación de disposiciones más favorables.

Asimismo, especial mención merece los principios que engloban esta ley, entre los que destacan el principio de eficacia, el principio de coordinación y, por supuesto, el principio de participación, ordenándose así tanto las actuaciones de las diversas Administraciones Públicas con competencias en materia preventiva, como la participación necesaria en dicha actuación de empresarios y trabajadores (a través de sus organizaciones representativas), destacándose aquí la Comisión Nacional de Seguridad y Salud en el Trabajo, configurado como instrumento privilegiado de participación en la formulación y desarrollo de la política en materia preventiva. No obstante, sin perjuicio de todo lo anterior, con la finalidad de crear y fomentar lo que vino a denominarse una "auténtica cultura preventiva», la propia ley involucra directamente a la sociedad en su conjunto, lo que quizás debería recordarse y difundirse dada la situación excepcional de crisis sanitaria que nos encontramos atravesando.

Sin perjuicio de lo comentado, con el afán de imposición de una verdadera cultura preventiva, en plena vinculación con la responsabilidad en materia de prevención de riesgos laborales, localizamos cuatro tipos de responsabilidades 
con las que poder generar un temor real para el obligatorio cumplimiento de la normativa (tanto desde la perspectiva empresarial como desde la perspectiva del trabajador) (Montoya, 2004): la responsabilidad administrativa (responsabilidad pública); la responsabilidad penal (responsabilidad pública); la responsabilidad civil (responsabilidad privada); y las responsabilidades de Seguridad Social (nos referiremos especialmente a la responsabilidad de naturaleza compleja) (Monereo, 1992: 89). En estas cuatro responsabilidades se parte de un presupuesto inexcusable: el incumplimiento por acción o por omisión (Valdeolivas, 2012: 21 y 22).

El artículo 14 de la LPRL, viene a imponer, tanto al empresario como al trabajador, una serie de obligaciones con las que garantizar la seguridad y la salud en el trabajo (Ortega y Guindo, 2020: 89). La transgresión de la protección de ambos frente a los riesgos laborales implicará un incumplimiento de la normativa, ya sea por acción o por omisión. Este precepto viene a confirmar que todos los trabajadores tienen derecho a una protección eficaz en materia de seguridad y salud que viene a ser correlativo al deber del empresario de protección de los trabajadores frente a los riesgos laborales. Asimismo, este deber u obligación del empresario también es transportable al ámbito de las Administraciones públicas respecto del personal a su servicio. Continua el precepto confirmando que los derechos de información, consulta y participación, formación en materia preventiva, paralización de la actividad en caso de riesgo grave e inminente y vigilancia de su estado de salud, tal como veremos a lo largo del desarrollo de este texto, forman parte del derecho de los trabajadores a una protección eficaz en materia de seguridad y salud en el trabajo.

En cumplimiento del deber de protección, es el empresario quién deberá garantizar la seguridad y la salud de los trabajadores a su servicio en todos los aspectos relacionados con el trabajo. A estos efectos, en el marco de sus responsabilidades, el empresario realizará la prevención de los riesgos laborales mediante la integración de la actividad preventiva en la empresa (cultura de prevención) y la adopción de cuantas medidas sean necesarias para la protección de la seguridad y la salud de los trabajadores, con determinadas especialidades que habrán de tenerse en cuenta en materia de plan de prevención de riesgos laborales, evaluación de riesgos, información, consulta y participación y formación de los trabajadores, actuación en casos de emergencia y de riesgo grave e inminente, vigilancia de la salud, y mediante la constitución de una organización y de los medios necesarios en los términos de los servicios de prevención (capítulo IV) de la LPRL.

Es por ello que el empresario deberá desarrollar una acción permanente de seguimiento de la actividad preventiva con el fin de perfeccionar de manera continua las actividades de identificación, evaluación y control de los riesgos que no se hayan podido evitar y los niveles de protección existentes; asimismo, el em- 
presario deberá de disponer de lo necesario para la adaptación de las medidas de prevención a las modificaciones que puedan experimentar las circunstancias que incidan en la realización del trabajo. Por otro lado, todas las obligaciones de los trabajadores establecidas en esta ley, la atribución de funciones en materia de protección y prevención a trabajadores o servicios de la empresa y el recurso al concierto con entidades especializadas para el desarrollo de actividades de prevención vendrán a complementar las acciones del empresario, sin que por ello le eximan del cumplimiento de su deber en esta materia, sin perjuicio de las acciones que pueda ejercitar, en su caso, contra cualquier otra persona (García, 2020: 543 y siguientes). Asimismo, el coste de las medidas relativas a la seguridad y la salud en el trabajo no deberá recaer en modo alguno sobre los trabajadores.

Así, en la propia normativa de prevención podemos localizar un elenco de obligaciones de obligado cumplimiento como antesala de la "cultura preventiva». Sin embargo, avanzando algo más, parece ser que la verdadera cultura de prevención por incumplimiento del empresario se localiza en el complejo sistema de responsabilidades existentes. En este sistema se recoge un modelo de responsabilidad mixta (como veremos a lo largo del desarrollo de este texto): el incumplimiento por los empresarios de sus obligaciones en materia de prevención de riesgos laborales dará lugar a responsabilidades administrativas, así como, en su caso, a responsabilidades penales y a las civiles por los daños y perjuicios que puedan derivarse de dicho incumplimiento (artículo 42 de la LPRL); sin olvidar el recargo de prestaciones como supuesto especial de responsabilidad de Seguridad Social.

\section{El recorrido del derecho de participación en la empresa: de la participación general de los trabajadores en la empresa al modelo de participación en la cultura de la prevención de riesgos laborales}

El «objeto» o ámbito de la participación es la «empresa» como organización de una actividad económica determinada (Monereo, 2017: 796 y siguientes). La empresa, como se indicó, está en un proceso de permanente reestructuración desde todas sus perspectivas (Monereo y Ortega, 2020: 386 y siguientes). Las compañías transnacionales sufren transformaciones de enorme complejidad con gran rapidez. Estas ya no son las tradicionales empresas multinacionales con estructuras decisorias rígidamente jerarquizadas, sino más flexibles y relativamente descentralizadas, de orden esencialmente "multidivisional». Esto les dota de una singular capacidad de adaptación a las variaciones del mercado, verificando las nuevas tendencias y adecuando a ello el sistema de producción. Para ello se organiza a través de unidades o divisiones empresariales articuladas por el eje de un centro de decisión unitaria, pero fluido. Esta metamorfosis de la empresa 
transnacional ha sido facilitada por la progresión de las nuevas tecnologías en el marco de la «sociedad de la información». Las empresas transnacionales (pero también las nacionales) tienden a adoptar estructuras cada vez más descentralizadas en las cuales prevalece, sin embargo, diversas formas de relación de colaboración interempresarial, formando redes de colaboración; lo que da lugar a una multiplicidad de formas de vinculación horizontal y vertical entre las empresas, en paralelo con las transformaciones de los procesos de producción y comercialización de los productos. Se forman «redes» flexibles entre las diversas unidades productivas. Su relación de base es la «especialización flexible» de la producción, dando lugar a la formación de plantas industriales preparadas para responder rápidamente a las variables exigencias de los mercados. Este modelo flexible de organización de la producción es el propio del modelo postfordista como paradigma organizativo y técnico-industrial emergente.

Normalmente se tiende a una reducción formal de la dimensión de la empresa, pero existe un alto grado de integración o colaboración entre las distintas unidades productivas (relativamente) autónomas que están implicadas en los nuevos complejos empresariales. En el lado «interno» a la empresa (esto es, desde el punto de vista de su estructura interior y de los elementos que están integrados en ella), el modelo posfordista produce un cambio en el rol productivo del trabajo humano basado ahora en maximizar la autonomía y la creatividad de los operadores. Este modelo se basa precisamente en la mayor participación de los trabajadores en la delimitación del trabajo, en los métodos de producción y en los flujos de producción en atención a las variaciones del mercado.

La participación exigida (desde una perspectiva sociológica y vinculada a indicadores de participación y a las principales características de gestión preventiva y sociodemográficas, véase Payá y Beneyto, 2018; Payá y Beneyto, 2019) es, sin embargo, concebida como elemento estrictamente funcional a la rentabilidad y no en los términos de la democracia industrial como instrumentación de mecanismos encaminados a compartir y distribuir el poder en las organizaciones empresariales. Desde el punto de vista de la participación «funcional» o instrumental (presidida por la racionalidad instrumental), la participación comporta la utilización de tecnologías sociales (de «ingeniería social», diría Roscoe Pound) dirigidas a transformar y moderar los comportamientos conflictivos de los trabajadores para conseguir la cooperación y la aceptación de las decisiones empresariales en elaboración del orden en la producción. Es decir, sirve funcionalmente como medio adecuado para fomentar la cooperación y la integración de los agentes, expandiendo el control directivo sobre relaciones de poder en las organizaciones empresariales. En este enfoque funcionalista la participación es percibida y practicada no tanto como un derecho democratizador (incluido en la noción de ciudadanía industrial) como una útil facultad instrumental al servicio de la dirección del complejo empresarial que se encamina esencialmente al mayor rendimiento y competitividad de la organización productiva. 
Por contraposición a la concepción de la participación como mera técnica instrumental directiva, se sitúa las concepciones que se vinculan a la democracia industrial, donde la razón de la eficiencia productiva se combina con la pretensión explícita de transformar los equilibrios de poder en el proceso de toma de decisiones empresariales, y la mayor intervención de los trabajadores en el proceso de trabajo. Se trataría de cambiar las tradiciones relaciones jerarquizadas y asimétricas entre dirección y trabajador, en el marco de un proceso de democratización, yendo más allá de una simple modernización de los modos y dispositivos en virtud de los cuales se facilitaría el ejercicio del poder unilateral de la dirección. No se trataría de obtener sólo un orden y consentimiento en la producción; sino de hacer partícipes a los trabajadores de la marcha de la empresa participando activamente en el poder de decisión. De este modo, los mecanismos de participación en la lógica de la democratización de las organizaciones empresariales no serían meras tecnologías sociales que persiguen garantizar al máximo la motivación e integración de los trabajadores y legitimar las decisiones de la empresa, sin que la participación sea co-participar en el poder decisorio. El modelo de participación orientado hacia la democracia industrial persigue, pues, una más equilibrada distribución de la autoridad entre el capital y el trabajo en la organización empresarial. Una forma de gestión participativa que trataría de realizar los valores de la democracia en la empresa, sin limitarse (pero tampoco sin ignorar) a justificar o legitimar las prerrogativas de la dirección: no sería un simple medio para alcanzar objetivos satisfactorios en el campo de la producción en términos de calidad. En ese marco puede considerarse una expansión consecuencia de la democracia la vinculación del trabajo en la gestión de la empresa y del proceso productivo (Monereo y Ortega, 2020: 386 y siguientes).

Resulta, así, que la participación de los trabajadores es una noción polisémica que presenta una multiplicidad de contenidos y versiones sobre su alcance y sobre los dispositivos que han de ser puestos en práctica. Por ello el modelo de participación depende de la conformación del propio modelo de relaciones industriales, porque en atención a éste se podrá apreciar los objetivos a perseguir por las políticas de participación en la dirección de la empresa. Por otra parte, los nuevos modelos productivos y la posible descentralización de la producción, viene acompañada de una mayor integración financiera (no contrarrestada por las formas de participación financiera colectiva o individualizada), al propio tiempo que la reducción de la dimensión de las fábricas se hace compatible con la mayor dimensión de las empresas como organizaciones de la actividad económica. La «navaja analítica» aplicada a la conformación actual de las empresas más innovadoras evidencia esa tendencia emergente. El sistema de producción flexible permite una rápida y mejor adaptación de la producción a la demanda, un alto potencial de innovación, una reducción de trabajadores «internos» y, en fin, sistemas de control basados en redes descentralizadas. Estas nuevas formas de organización y colaboración empresarial utilizan renovadas formas y reglas jurídicas. 
En el nuevo derecho de la producción se utilizan las formas jurídicas tradicionales, pero en la creación de un espacio jurídico transnacional interviene de forma decisiva el establecimiento de una red de acuerdos formales e informales celebrados entre compañías y cadenas de empresas. Junto a las formas jurídicas del Derecho Interestatal se acrecienta el peso de la tradicional Lex Mercatoria (Monereo, 2017b: 77), en virtud de la cual las empresas transnacionales se autorregulan eludiendo interferencias de los Estados nacionales. El derecho de la producción resultante es el que asume una posición central y es capaz de determinar el sentido de las transformaciones del mismo Derecho positivo estatal, cuyo derecho económico, mercantil, laboral y fiscal queda fuertemente condicionado por las prácticas autónomas de los grupos empresariales privados. El mercado y los actores económicos dominantes (entre los que entran la constelación de empresas transnacionales) limitan los márgenes de decisión de los Estados miembros. En este sentido la influencia de la racionalización económica (de sus principios y valores) es determinante de la organización del Sistema Social y Político. Siendo, así, que el fenómeno se acrecienta conforme avanza el proceso de transnacionalización de los mercados.

Si para los Estados es ya difícil acometer procesos de heteroregulación de las actividades económicas; para los trabajadores resulta más difícil articular mecanismos de control y de participación sobre los complejos empresariales. Lo que se hace prevalecer es una lógica propia de los sistemas autorregulados entre los complejos empresariales, y, de forma subordinada, entre los actores sociales (empresarios y representaciones asociativas o unitarias). Las condiciones del mercado cambian con gran rapidez, de manera que la presión competitiva de las empresas se incrementa, condicionando los sistemas normativos de los Estados. Proliferan los acuerdos «microcorporativistas» (coherentes con la conformación de los complejos empresariales como unitas multiplex), más flexibles, descentralizados y eficientes que los tradicionales grandes acuerdos «macrocorporativos» que caracterizaron a la racionalidad del fordismo. El objetivo comúnmente perseguido por la nueva política empresarial es la flexibilidad como fin preferente, haciendo posible conseguir una capacidad general de las empresas para reorganizarse en respuesta directa a las fluctuaciones de su medio ambiente. Es la doble vertiente del Derecho reflexivo (implicado en los procesos de autorregulación), el cual encuentra su manifestación el Derecho económico empresarial y en el Derecho convencional del Trabajo. En este marco, la Unión Europea, con su Tratado instituyente de la Constitución Europea, es una manifestación significativa de un orden político de carácter «posthobbesiano", dotado de un centro de decisión política unitaria y una pluralidad de instancias estatales soberanas, las cuales han consentido en ceder ámbitos relevantes de sus competencias soberanas («autolimitación» de poderes normativos soberanos detentados por los Estados miembros).

Los modelos de organización empresarial para afrontar los retos de la competitividad de escala exigen una mayor implicación de los trabajadores en el pro- 
ceso de toma de decisiones empresariales. La razón económica de la competitividad prevalece notoriamente respecto de la razón participativa dentro de las aspiraciones inherentes a los modelos de la llamada «democracia industrial». Desde ese enfoque funcional o instrumental de la participación se sitúa hoy el problema de la intervención e influencia de los trabajadores en el gobierno de la empresa. Esto es, desde la perspectiva de una participación debilitada, no desde una participación fuerte. Ello sin perjuicio de que existan ámbitos de participación cogestional fomentados desde la nueva cultura jurídica empresarial de la participación.

La perspectiva actual de fomento de las distintas formas de participación e implicación de los trabajadores en la empresa adolece de ese enfoque de racionalidad instrumental, donde predomina la defensa del principio axial de eficiencia o economicidad. La empresa global (como nuevo modelo de organización de la actividad económica apoyado en la innovación tecnológica) aparece como una institución económica en la que prevalece la lógica del mercado. En este sentido se ha producido también un cambio en la ideología jurídica de la participación que ha acompañado a las recientes transformaciones del capitalismo, en una secuencia que va desde el predominio del conflicto hacia el de la cooperación (aunque siempre desde la defensa de los propios intereses de los trabajadores).

No se olvide que en sí el mercado global obedece a estrategias de orden político e ideológico, como ocurre con el mismo paradigma de empresa global flexible y descentralizada. El mercado moderno es una unidad jurídico-económica de relaciones de intercambio, siendo su estructura el reflejo de una decisión político-jurídica.

Los nuevos modelos de empresa en los países desarrollados parecen exigir formas de participación más cooperativa en lo que respecta a la solución de los problemas de la empresa y de la organización de las relaciones laborales. Pero, al propio tiempo, la segmentación de los trabajadores en la misma empresa puede plantear nuevas formas de conflictividad (trabajadores permanentes/trabajadores temporales; trabajadores «internos» y trabajadores «externos» que prestan servicios en el mismo centro de trabajo; etcétera). También la apertura del conflicto queda abierta manifiestamente en los procesos de reestructuración, que a menudo desembocan en despidos masivos, y, en relación a ello, en los procesos de «deslocalización» de las grandes sedes empresariales en la dirección de reducir costes mediante el abaratamiento de la mano de obra. Estos procesos pueden ser tratados mediante el diálogo, la consulta, la participación institucional y la negociación colectiva, pero operan, sin duda, sobre un entramado altamente conflictivo de intereses en juego. Por consiguiente, la realidad cooperativa no reside en la desaparición del conflicto sino en el tipo de método más adecuado para su tratamiento. El conflicto es connatural a las relaciones laborales, y en tanto persista el régimen salarial el conflicto existirá entre el trabajo y capital como fuer- 
zas productivas. En relación a ello, la empresa como organización es en sí misma una estructura de dominación, presidida por relaciones de poder, con inevitable apertura hacia el conflicto, el cual puede ser, sin embargo, afrontado desde ópticas distintas (de ruptura o de reforma; de disolución; o de institucionalización, esto es, de encauzamiento jurídico e institucional de la conflictividad emergente en cada momento o etapa histórica) (Monereo, 2017: 799).

En la dialéctica conflicto/pacto, reivindicación/cooperación, en un modelo evolucionado («civilizado») de relaciones laborales se tiende a hacer prevalecer el método del pacto o de la cooperación. Por lo demás, existen ámbitos de las relaciones laborales en los que es posible encontrar espacios para una toma de decisiones por vía co-decisional, y en los que, en términos de principio, es posible una implicación directa y no necesariamente de conflicto abierto (v.gr., seguridad y salud laboral; nuevas tecnologías). En estos ámbitos la lógica de la cooperación puede desplegarse fácilmente y de modo funcional.

Con todo, la penetración de la cultura de la participación es mayor en el desenvolvimiento de las relaciones colectivas y sindicales en la empresa. La vía del consenso ha sido un instrumento realmente útil que ha facilitado (desde el punto de vista socio político) los procesos de reestructuración y renovación tecnológica. La participación ha sido un valor ańadido en dichos procesos. Los trabajadores han podido intervenir en las decisiones preventivamente o, en su caso, han reducido o amortiguado sus consecuencias más nocivas. El personal de la organización productiva cuenta con una estructura representativa dotada de facultades de información y consulta ante las posibles decisiones de reestructuración empresarial que puedan afectarles; debiéndose realizar la información y la consulta en tiempo útil y con los contenidos apropiados para que los representantes de los trabajadores estén en condiciones de intervenir en el proceso de tomas de decisiones de reestructuración (véase, con referencia a los Comités de Empresa Europeos, SSTJCE 29 marzo 2001 (Caso «Bofrost») y 13 enero 2004 (Caso «Kühne \& Nagel»).

El Tratado de la Constitución Europea parece establecer un modelo abierto de participación, pero desde una fórmula ciertamente debilitada. Esto es, a título sobre todo de derechos de información y consulta, y tan sólo con una tímida referencia a la «cogestión» o codecisión institucional. Su concreción o desarrollo legislativo y su aplicación práctica queda fuertemente condicionado por la realidad de formas de empresa "difusas», en régimen de colaboración o integración, u organizadas de manera descentralizada. Una empresa caracterizada por el "poliformismo», que, además de ser difusa y descentralizada, se sitúa en constante cambio (se inviste y "des-inviste» rápidamente) y reestructuración permanente, lo cual plantea nuevos problemas respecto a su dirección y a los mecanismos de influencia o participación de los trabajadores en ella, en su calidad de «partícipes» de pleno Derecho. Se ha reforzado la libertad de empresa (que in- 
cluye la libertad de gestionar la empresa libremente) y se invoca continuamente el «interés objetivo de la empresa», tanto desde el punto de vista judicial como desde la perspectiva de la legislación (especialmente de la reestructuración de las empresas; en términos de viabilidad empresarial, posición competitiva de la empresa, etcétera). En muchos casos, las empresas aparecen como un centro de actividades (a menudo desmaterializado) dependiente de decisiones adoptadas en centros de decisión de grupos nacionales o multinacionales (adviértase el fenómeno de la «deslocalización»). Las grandes compañías o empresas transnacionales actúan como un nuevo sujeto histórico sobreañadido a los Estados y clases sociales de antaño que ejercen su dominio en el nuevo espacio económico-político de la globalización.

El lugar de la participación, su modelo, dependerá también de la estrategia que se siga en la determinación y «selección» de los modelos productivos: caben los viejos modelos productivos; y también las opciones extremas de estrategia de reducción permanente de los costes, por un lado, y, por otro, la estrategia de innovación y flexibilidad. El modelo de participación no es en absoluto indiferente a dichos modelos, sino que está relativamente condicionado por ellos. La vida económica actual se caracteriza por la transformación de la organización de las empresas, donde el cambio se ha instalado en términos de transformación jurídica (supuestos de fusión y escisión de sociedades), económica (modificaciones de condiciones de trabajo y despidos por causas de funcionamiento o adaptación), o bien como cambios de su estructura financiera (cambios de control, políticas de salvamento o saneamiento). Estas transformaciones de las estructuras jurídicas y económicas de las empresas se producen dentro de unas reglas de juego jurídica e institucionalmente predeterminadas que hoy se encuentran en proceso de adaptación "subordinada» (esto es, dependiente en gran medida de las exigencias empresariales en un ordenamiento jurídico decididamente proempresarial), cuando no en abierta situación de crisis de identidad y de eficiencia. Estas reglas del ordenamiento laboral reflejan un cierto desfase de ritmo entre la constitución económica y la constitución social y participativa del trabajo en el mundo de las relaciones de producción. La razón económica evoluciona de modo más coherente que la razón social en los procesos de reorganización y transnacionalización de la economía. Si no se alcanza un equilibrio entre esas dos razones, que están en la base de la función político-jurídica del Derecho del Trabajo, los derechos participativos estarán vaciados de contenido y tan sólo asumirán una función legitimadora de decisiones de gobierno empresarial que se imponen unilateralmente a los trabajadores, sin que éstos puedan intervenir incisivamente en la estrategia empresarial. La dirección de la empresa acabará por instaurar un sistema de gestión autónomo de la organización productiva en relación al conjunto del personal (Monereo y Ortega, 2020, 390).

Es de realzar que se ha perdido en gran medida la idea originaria de la «reforma de la empresa»; sustituida por la idea de una participación funcional hacia 
la empresa como organización de actividades económicas orientadas al máximo beneficio (la empresa como centro de beneficios que otorga preferencia al «valor económico» de la competitividad). Se fomenta la "cultura de la participación» como elemento instrumental al servicio del principio axial de eficiencia económica entre los elementos personales que quedan implicados en la organización productiva. Basta reparar en la fórmula, "necesidades objetivas de la empresa» como condicionante necesario de la misma racionalidad de sus formas de dirección y gestión.

Con todo, lo que se está produciendo es una crisis del paradigma o modelo de empresa originario, dominado por una empresa centralizada, jerarquizada y unidireccional en su estructura directiva. Actualmente, la empresa continúa siendo ámbito de organización de las relaciones de trabajo y marco de referencia del Derecho Social del Trabajo. Pero la empresa se ha transformado intensamente, porque la empresa deja de ser una estructura estrictamente descentralizada (los procesos de exteriorización de la mano de obra con la subcontratación, la empresa en red -con una nebulosa de contratistas, proveedores, prestatarios de servicios externos, etcétera-, la empresa «virtual», las empresas de trabajo temporal, la cesión de trabajadores en las estructuras de grupo, etcétera; lo que determina que la empresa sea cada vez más difusa) y jerarquizada (las nuevas formas de trabajo requieren la implicación de los trabajadores, el trabajo de calidad y la asimilación en el perfil de cualificación de las nuevas tecnologías). En tal sentido el problema que se plantea es el del espacio "empresarial» de la participación de los trabajadores, a menudo, su misma identificación; y otro tanto ocurre respecto a la identificación de los auténticos centros de decisión empresarial.

La cuestión se suscita a propósito del hecho obvio del carácter difuso y no transparente de la empresa contemporánea y a su orientación hacia el beneficio. La transparencia opera respecto a los trabajadores, pero también en cuanto a los accionistas; a menudo, unos y otros, se ven desplazados por los nuevos tecnócratas, los «managers», bajo los nuevos paradigmas de dirección empresarial, y directivos con alta capacidad de adaptación y movilidad. El poder - su autonomía - de los dirigentes empresariales se acrecienta, por lo demás, en el marco de la globalización de la economía marcada por la desregulación, que exige la adopción de decisiones rápidas, a pesar de comprometer la posición competitiva de la empresa. Cómo, entonces, garantizar que los derechos y libertades constitucionales penetren en esa "empresa difusa» (y tendencialmente «intransparente»); y entre esos derechos está el de participación, en la idea de un autogobierno más participativo de la empresa moderna (Monereo, 2017: 801 y siguientes).

Se produce aquí una fragmentación de la colectividad del trabajo en la empresa. Las estructuras representativas y la participación de los trabajadores en esas nuevas formas de organizar la empresa no pueden superar la posición estructural de subordinación del trabajo ni tampoco la reconstrucción del mundo 
del trabajo con las nuevas formas empresa y de trabajar, pero sí pueden contrarrestar muchas de sus derivaciones más negativas. Entre otras cosas, porque en no pocos casos las nuevas prácticas de gestión empresarial son formas que han permitido esquivar a los sindicatos (como pretensión efectiva o como elemento objetivo que lo permite o posibilita). Las prácticas de organización empresarial no son un elemento extraño a las políticas de poder entre los actores sociales.

Estos son los grandes dilemas que se plantean también en lo que se refiere a la instrumentación del derecho de participación de los trabajadores en la empresa (afectando así a la prevención de riesgos laborales). Los derechos participativos, de los trabajadores o de sus representantes (éstos encarnan jurídicamente la defensa de los intereses del personal de la empresa de pertenencia) son elementos necesarios del modelo de democratización postulado por el constitucionalismo democrático-social y su cristalización en la idea-fuerza de la ciudadanía de la empresa (que se juridifica a través de la garantía de los derechos generales y específicos de los trabajadores en la misma o en su interior). Ese modelo determinó la crisis "política» del paradigma de autoridad y unidireccionalidad de la empresa; con todo un sistema de límites de los poderes empresariales discrecionales y la instrumentación de modos participativos de ejercicio. En este contexto, los derechos de información, consulta y participación institucional (cogestión o codecisión) han permitido controlar el ejercicio de los poderes de la dirección de la empresa y co-decidir en importantes materias. Su eficiencia, no obstante, queda comprometida por el modelo de dirección unilateral que se contrapone a la visión pluralista de la empresa. Ésta última postula un gobierno directivo que tenga en cuenta la pluralidad de intereses presentes en su interior. Si se desea ir más allá de una participación «simbólica» (cuando no decididamente retórica) debe tomarse en serio el derecho de participación de los trabajadores en la dirección de la empresa y asegurar en todo caso el principio de responsabilidad social en el ejercicio de actividades empresariales. El juego que pueda tener el «interés de la empresa» es muy distinto según el modelo de gestión en que se encuadre. Desde un modelo unidimensional o monista del interés de la empresa, la dirección se sitúa en términos antitéticos respecto al personal y a las estructuras representativas que lo institucionalizan en términos jurídicos. Por el contrario, desde un modelo pluralista, el interés de la empresa puede ser un elemento que delimite puntos de encuentro o desencuentro en su dinámica de funcionamiento. El modelo pluralista se caracteriza por la construcción jurídica de una "constitución del trabajo" en la empresa, que garantiza los derechos de los trabajadores en su interior, y, especialmente, en los procesos de reestructuración productiva. Las nuevas culturas de empresa tratan de concentrar los esfuerzos en la integración y en la realización de los objetivos empresariales, buscando aquellas áreas de interés común.

Actualmente, se asiste a una crisis del modelo pluralista, donde las políticas de flexibilidad gestional ponen en cuestión sus postulados y sus ventajas. 
La política directiva de la empresa parece otorgar una máxima preferencia a las exigencias del mercado y de la competitividad en una economía global. En ese contexto se enmascaran opciones decisorias unidireccionales bajo el camuflaje de un planteamiento tecnocrático de la eficiencia de la empresa (racionalización tecnocrática). El enfoque funcionalista ve en la empresa un sistema de contratación articulada alrededor de una actividad económica, haciendo difuso el elemento organizacional en sí que es soporte de la empresa como institución económica del capitalismo actual. Este paradigma o modelo de empresa tiende a anular la eficiencia y operatividad práctica de los derechos de información consulta, y participación institucional o en forma de codecisión, puesto que operan respecto de una realidad empresarial presupuesta que tiende a difuminarse. En las nuevas formas de organización de la empresa, nociones como centro de trabajo y centro de decisión como referentes de la organización y actividad de las instancias representativas del personal se difuminan en los procesos de desmaterialización y disgregación que presiden las actuales operaciones de reestructuración empresarial. La progresión de esta tendencia conduce, de suyo, a vaciar de contenido y eficacia los derechos de información, consulta y co-decisión (basta reparar en la dificultad de garantizar el principio de transparencia informativa de la empresa en relación al personal, cuando no a las mismas instituciones representativas de los trabajadores en el marco de organizaciones empresariales «difusas» $y$, a menudo, «virtuales»).

En esta perspectiva, el derecho social de participación (tanto más en un sentido «fuerte») presupone el diálogo y una cierta aceptación común de las necesidades de la organización productiva. Ello comporta un clima de cooperación entre las diversas partes implicadas y comprometidas en la organización económica. ¿Y cuál es el modelo actual vigente de derechos de participación en materia de prevención de riesgos laborales en España? El artículo 33 de la LPRL se refiere expresamente a la obligación del empresario de consultar a los trabajadores la adopción de las decisiones relativas a: la planificación y la organización del trabajo en la empresa y la introducción de nuevas tecnologías, en todo lo relacionado con las consecuencias que éstas pudieran tener para la seguridad y la salud de los trabajadores, derivadas de la elección de los equipos, la determinación y la adecuación de las condiciones de trabajo y el impacto de los factores ambientales en el trabajo. b) La organización y desarrollo de las actividades de protección de la salud y prevención de los riesgos profesionales en la empresa, incluida la designación de los trabajadores encargados de dichas actividades o el recurso a un servicio de prevención externo. c) La designación de los trabajadores encargados de las medidas de emergencia. d) Los procedimientos de información y documentación. e) El proyecto y la organización de la formación en materia preventiva. f) Cualquier otra acción que pueda tener efectos sustanciales sobre la seguridad y la salud de los trabajadores. 
Al hilo de lo anterior, el artículo 34 de la LPRL se refiere expresamente a los derechos de participación y representación de los trabajadores en cuestiones relacionadas con la prevención de riesgos laborales. Es así que, en las empresas o centros de trabajo que cuenten con seis o más trabajadores, la participación de éstos se canalizará a través de sus representantes y de la representación especializada que se regula en este capítulo. Es a los Comités de Empresa, a los Delegados de Personal y a los representantes sindicales a quiénes les corresponden la defensa de los intereses de los trabajadores en materia de prevención de riesgos en el trabajo. Es por ello que el capítulo $\mathrm{V}$ de este texto normativo viene a regular la «consulta y participación de los trabajadores».

Por tanto, se construye así el derecho de los trabajadores a participar en la empresa en cuestiones relacionadas con la prevención de riesgos laborales, lo que vendrá a realizarse a través de los Delegados de Prevención (representantes de los trabajadores en la empresa con funciones específicas en materia de prevención de riesgos en el trabajo) (Alegre, 2019: 59; García, 2009: 121). Delegados de Prevención que serán designados por y entre los representantes (legales, unitarios) del personal. En este sentido, su número varía paralelamente al de los miembros de comités o delegados debiendo estar en consonancia con la siguiente escala: de 50 a 100 trabajadores: 2; de 101 a 500 trabajadores: 3; de 501 a 1.000 trabajadores: 4; de 1.001 a 2.000 trabajadores: 5; de 2.001 a 3.000 trabajadores: 6; de 3.001 a 4.000 trabajadores: 7; y de 4.001 en adelante: 8 . Teniendo en cuenta que, en las empresas de hasta 30 trabajadores, el Delegado de Prevención será el Delegado de Personal; de 31 a 49 trabajadores el Delegado de Prevención será elegido por y entre los Delegados de Personal. En los centros de trabajo que carezcan de representantes de personal (representación legal o unitaria) por no alcanzar la antigüedad para ser electores o elegibles, los trabajadores podrán elegir por mayoría a un trabajador que ejerza las competencias de Delegado de Prevención (disposición adicional cuarta de la LPRL). Asimismo, brevemente debe destacarse al Comité de Seguridad y Salud, órgano paritario y colegiado de participación destinado a la consulta regular y periódica de las actuaciones de la empresa en materia de prevención de riesgos. Como órgano paritario está formado por los Delegados de Prevención y por el empresario y/o sus representantes en número igual al de Delegados de Prevención. Quedará constituido en todas las empresas o centros de trabajo que cuenten con 50 o más trabajadores.

Dicho lo anterior, quizás, la mejor cultura de prevención y participación sea un modelo fuerte de responsabilidad de la empresa y trabajador por incumplimiento de la ley: un modelo generador de temor y desconfianza con el que conseguir el auto-cumplimiento del modelo de prevención cultural en empresas y por empresarios y trabajadores. Es por ello que, a continuación, nos vemos obligados a referirnos al actual modelo de responsabilidades vigentes (Administrativa, Penal, Civil y de Seguridad Social) y su aplicación en la práctica judicial. 


\section{El modelo de responsabilidad en materia de prevención de riesgos laborales: administrativa, penal, civil y recargo de prestaciones como supuesto especial de responsabilidad de Seguridad Social}

Refirámonos, a continuación, al modelo de responsabilidad existente en materia de prevención de riesgos laborales (Ortega, 2020: 841 y siguientes). Para ello tendremos que analizar detenidamente todas las posibilidades de responsabilidad que podemos encontrar en la práctica judicial.

\subsection{Responsabilidad administrativa}

La responsabilidad administrativa es una responsabilidad de naturaleza pública, en cuanto que se desenvuelve en el contexto de la relación entre los particulares y los poderes públicos. El carácter público de esta responsabilidad se refleja en su contenido como en la exigencia de responsabilidad, pues debe destacarse que sus consecuencias son típicamente sancionadoras y porque para su exigencia han de respetarse los principios básicos del derecho sancionador: legalidad, tipicidad, culpabilidad, presunción de inocencia, non bis in ídem, etcétera (García y Rodríguez, 2015: 450). Los fines de la responsabilidad administrativa son dos: el sancionador y el preventivo (Pérez, 2020: 19). La responsabilidad administrativa posee finalidad sancionadora marcada por el carácter tuitivo que preside la propia legislación laboral, justificando el intervencionismo administrativo en la necesidad de vigilar el cumplimiento del orden social (Fernández, 2014: 1 y siguientes). Y tiene finalidad preventiva dado que la propia amenaza de la sanción opera como efecto disuasorio de la transgresión normativa y como potenciador del propio cumplimiento del deber de seguridad del empresario (García, 2006: 570). Ambas finalidades coinciden también en la responsabilidad penal, pero esta última posee una diferencia importante: el principio de intervención mínima.

El Real Decreto Legislativo 5/2000, de 4 de agosto, por el que se aprueba el texto refundido de la Ley sobre Infracciones y Sanciones en el Orden Social (en adelante, LISOS) viene a sancionar a los empresarios que incumplan la normativa en el orden social, entre otras cuestiones, por el incumplimiento de la seguridad y salud laboral. El artículo 5.2. LISOS determina que son infracciones laborales en materia de prevención de riesgos laborales:

Las acciones u omisiones de los diferentes sujetos responsables que incumplan las normas legales, reglamentarias y cláusulas normativas de los convenios colectivos en materia de seguridad y salud en el trabajo sujetas a responsabilidad conforme a esta ley.

La responsabilidad administrativa cumple fines sancionadores y represivos. Como puede comprobarse, la sanción principal es de carácter económico 
(multa), aunque también pueden existir otras sanciones más drásticas: el Gobierno o, en su caso, los órganos de gobierno de las Comunidades Autónomas con competencias en la materia, cuando concurran circunstancias de excepcional gravedad en las infracciones en materia de seguridad y salud en el trabajo, podrán acordar la suspensión de las actividades laborales por un tiempo determinado o, en caso extremo, el cierre del centro de trabajo correspondiente, sin perjuicio, en todo caso, del pago del salario o de las indemnizaciones que procedan y de las medidas que puedan arbitrarse para su garantía (artículo 53 LPRL).

La LISOS establece que son sujetos responsables de la infracción las personas físicas o jurídicas y las comunidades de bienes que incurran en las acciones $\mathrm{u}$ omisiones tipificadas como infracción en la presente ley y, en particular, las siguientes: el empresario en la relación laboral (apartado 1 del artículo 2 LISOS); los empresarios titulares de centro de trabajo, los promotores y propietarios de obra y los trabajadores por cuenta propia que incumplan las obligaciones que se deriven de la normativa de prevención de riesgos laborales (apartado 8 del artículo 2 LISOS); y las entidades especializadas que actúen como servicios de prevención ajenos a las empresas, las personas o entidades que desarrollen la actividad de auditoría del sistema de prevención de las empresas y las entidades acreditadas para desarrollar y certificar la formación en materia de prevención de riesgos laborales que incumplan las obligaciones establecidas en la normativa sobre dicha materia (apartado 9 del artículo 2 LISOS). Por tanto, en materia de prevención de riesgos laborales, no solo son responsables los empresarios; también los promotores y propietarios de obra y los trabajadores por cuenta propia que incumplan las obligaciones que se derive de la normativa de prevención; y las entidades especializadas que actúen como servicios de prevención ajenos a las empresas y las que desarrollen la actividad de auditoría del sistema de prevención. Sin perjuicio de lo anterior, la responsabilidad administrativa de los restantes sujetos a los que se refiere el artículo 2 LISOS posee un alcance más delimitado. Dicho alcance se debe a que, en la materia de salud y seguridad en el trabajo, no se alcanzan los niveles de generalidad que son propios del deber empresarial. Así, por ejemplo, la responsabilidad que se puede asumir por las entidades que desarrollan funciones de prevención, auditoría o formación queda cenida a las tareas específicas que realicen, como se deduce de los artículos 11, 12 y 13 LISOS (García y Rodríguez, 2015: 455).

Respecto a la posibilidad de que exista una pluralidad de empresarios, es evidente que la situación de colaboración entre varios empresarios donde los trabajadores desarrollen su actividad en dependencias de un empresario diferente o con trabajadores autónomos de otras empresas, son supuestos a los que debemos de referirnos. Partimos del artículo 42 LISOS, precepto que solo se refiere a los supuestos de responsabilidad en casos de cesión de trabajadores a través de ETTs y subcontratación. Por tanto, no contempla todos los supuestos del artículo 24 LPRL; sin perjuicio de lo anterior, a partir de este precepto puede de- 
ducirse la existencia de responsabilidad solidaria entre todos ellos (como regla general), así como del artículo 28.3 de la Ley 40/2015, de 1 de octubre, de Régimen Jurídico del Sector Público, que dispone:

Cuando el cumplimiento de una obligación establecida por una norma con rango de Ley corresponda a varias personas conjuntamente, responderán de forma solidaria de las infracciones que, en su caso, se cometan y de las sanciones que se impongan. No obstante, cuando la sanción sea pecuniaria y sea posible se individualizará en la resolución en función del grado de participación de cada responsable.

Respecto a los supuestos de subcontratación, el artículo 24.3 LRPL sí que se refiere expresamente al mismo cuando establece que las empresas que contraten o subcontraten con otras la realización de obras o servicios correspondientes a la propia actividad de aquéllas y que se desarrollen en sus propios centros de trabajo deberán vigilar el cumplimiento por dichos contratistas y subcontratistas de la normativa de prevención de riesgos laborales (artículo 42.3 LISOS). Lo que también es aplicable a los supuestos de concesiones administrativas. En las relaciones de trabajo mediante empresas de trabajo temporal, y sin perjuicio de las responsabilidades propias de éstas, la empresa usuaria será responsable de las condiciones de ejecución del trabajo en todo lo relacionado con la protección de la seguridad y la salud de los trabajadores, así como del recargo de prestaciones económicas del sistema de Seguridad Social que puedan fijarse, en caso de accidente de trabajo o enfermedad profesional que tenga lugar en su centro de trabajo durante el tiempo de vigencia del contrato de puesta a disposición y traigan su causa de falta de medidas de seguridad e higiene (apartado 2 del artículo 42.3 LPRL).

Para la valoración del daño, debe partirse del artículo 5.2 LISOS. Este precepto establece que:

Son infracciones laborales en materia de prevención de riesgos laborales las acciones u omisiones de los diferentes sujetos responsables que incumplan las normas legales, reglamentarias y cláusulas normativas de los convenios colectivos en materia de seguridad y salud en el trabajo sujetas a responsabilidad conforme a esta ley.

Dicho precepto confirma la objetividad de la infracción administrativa en materia de salud y seguridad laboral: se valora el mero incumplimiento al margen de las consecuencias dañosas o no que se hayan producido por la correspondiente acción u omisión. No se valoran, por tanto, ni la existencia de dańos, ni la gravedad de los mismos. En definitiva, para la existencia de dańo se considera suficiente la infracción o incumplimiento de la normativa. Para la imputación de la culpabilidad al sujeto infractor deberá probarse el incumplimiento y la autoría (artículo 53.1 de la Ley 39/2015, de 1 de octubre, del Procedimiento Administrativo Común de las Administraciones Públicas). Pero, como ha quedado 
claro, no se requiere al sujeto infractor negligencia o descuido; es suficiente con la mera infracción por falta de cuidado o atención o por acción u omisión de las reglas de seguridad y salud en el trabajo.

Al hilo de lo anterior, desde inicios de los años noventa, la doctrina jurisprudencial ya establecía que:

La culpabilidad, en cuanto relación psicológica de causalidad entre agente y resultado típicamente punible, no es elemento esencial para la existencia de infracciones sancionables por las Autoridades Laborales en materia de Higiene y Seguridad en el Trabajo toda vez que lo sancionado en este ámbito es el mero incumplimiento de los preceptos con independencia de que la conducta infractora produzca o no material perjuicio y con autonomía también respecto a las responsabilidades que pudieran concurrir en los otros órdenes jurisdiccionales, civil, penal e incluso laboral (STS 17 de septiembre de 1991 [RJ 1991\8290] y STS 2 de julio de 1996 [199615605]).

Así pues, en el desarrollo de la actividad laboral de una empresa existe un deber de seguridad por parte del titular de aquella que:

Obliga a exigir al trabajador la utilización de los medios dispositivos preventivos de seguridad, impidiendo, si ello fuera necesario, la actividad laboral de quienes, por imprudencia o negligencia, incumplan el debido uso de aquéllos, incluso a través del ejercicio de la potestad disciplinaria (STS 23 de febrero de 1994 [RJ 199412225] y STS 22 de abril de 1989 [RJ 1989\2877]).

Y es que, la deuda de seguridad de la empresa con sus trabajadores no se agota con darles los medios normales de protección, sino que viene además obligada:

A la adecuada vigilancia del cumplimiento de sus instrucciones que deben tender no sólo, a la finalidad de proteger a los trabajadores del riesgo genérico que crea o exige el servicio encomendado, sino además de la prevención de las ordinarias imprudencias profesionales (STS 22 de octubre de 1982 [RJ 1982\5794]).

Resaltándose que, como contrapartida a la facultad organizadora de la empresa por su titular, sobre éste recae la escrupulosa observancia de las medidas preventivas en la seguridad del trabajador, no siendo enervada tal obligación por la posible imprudencia del trabajador (STS 2 de julio de 1996 [RJ 199615605]). Parece ser que la culpa in vigilando es la que viene a actuar en relación al deber de seguridad del empresario hablando así de una responsabilidad cuasi-objetiva. No obstante, existen sentencias en las que se da paso a la consolidación de un firme principio culpabilístico (Mercader, 2020: 587):

Sostener lo contrario evidenciaría que dicha responsabilidad se ha cimentado sobre la base del acaecimiento de un resultado lesivo, sin considerar las causas determinantes del mismo, es decir, en atención a una responsabilidad objetiva basada en el 
resultado, lo cual resulta inadmisible, según se ha dicho antes, de acuerdo con la doctrina del Tribunal Constitucional y del Tribunal Supremo (STSJ Andalucía, Granada, 26 de enero de 2015 [JUR 2015\134968]).

De conformidad con lo anterior, posteriormente nos detendremos en analizar la responsabilidad empresarial que tenga su origen en circunstancias o hechos extraños por completo a la voluntad de los sujetos implicados, como pudieran ser los supuestos de estado de necesidad o de fuerza mayor (crisis sanitaria consecuencia del COVID-19) (Guindo, 2020: 173). En este sentido, el artículo 5.4 de la Directiva 89/391/CEE del Consejo, de 12 de junio de 1989, relativa a la aplicación de medidas para promover la mejora de la seguridad y de la salud de los trabajadores en el trabajo (Monereo y Moreno, 2018: 833; Monereo y López, 2016: 17; Monereo y López, 2015: 25), confirma que:

La presente Directiva no obstaculizará la facultad de los Estados miembros para establecer la exclusión o la disminución de la responsabilidad de los empresarios por hechos derivados de circunstancias que les sean ajenas, anormales e imprevisibles o de acontecimientos excepcionales, cuyas consecuencias no hubieren podido ser evitadas a pesar de toda la diligencia desplegada.

Sin perjuicio de lo anterior, la no exigencia de culpa por parte del empresario no quiere decir que éste no tenga consecuencia alguna. En definitiva, las infracciones en materia de prevención de riesgos laborales requieren de mero incumplimiento de la disposición legal, exista o no culpabilidad del infractor, sin que la imprudencia del trabajador exonere al empresario que no ha cumplido con sus obligaciones preventivas (García y Rodríguez, 2015: 462).

Para valorar la concurrencia de responsabilidad administrativa con otras posibles responsabilidades, debemos situarnos en el artículo 42 LPRL. El contenido de dicho precepto confirma la posibilidad de que concurran responsabilidad administrativa con responsabilidad penal, responsabilidad civil por daños y perjuicios, así como con el recargo de prestaciones económicas del sistema de la Seguridad Social que puedan ser fijadas por el órgano competente. No obstante, esta regla que declara la compatibilidad de responsabilidades requiere de una serie de matizaciones y especificaciones, especialmente, ante sanciones públicas (penales y administrativas).

Buena parte de los incumplimientos tipificados en los artículos 11 a 13 LISOS como infracciones administrativas podría encajar sin problema en los tipos delictivos de los artículos 316 y 317 CP, rechazándose así el principio non bis in idem. Pero, actualmente, el artículo 3 LISOS se refiere expresamente a la regla de aplicación del principio non bis in idem cuando establece los siguiente:

No podrán sancionarse los hechos que hayan sido sancionados penal o administrativamente, en los casos en que se aprecie identidad de sujeto, de hecho y de fundamento. 
Así, en los supuestos de concurrencia con el orden jurisdiccional penal, la Administración pasará el tanto de culpa al órgano judicial competente o al Ministerio Fiscal y se abstendrá de seguir el procedimiento sancionador mientras la autoridad judicial no dicte sentencia firme o resolución que ponga fin al procedimiento o mientras el Ministerio Fiscal no comunique la improcedencia de iniciar o proseguir actuaciones. Ahora sí: de no haberse estimado la existencia de ilícito penal, o en el caso de haberse dictado resolución de otro tipo que ponga fin al procedimiento penal, la Administración continuará el expediente sancionador administrativo en base a los hechos que los tribunales hayan considerado probados. La comunicación del tanto de culpa al órgano judicial o al Ministerio Fiscal o el inicio de actuaciones por parte de éstos, no afectará al inmediato cumplimiento de las medidas de paralización de trabajos adoptadas en los casos de riesgo grave e inminente para la seguridad o salud del trabajador, a la efectividad de los requerimientos de subsanación formulados, ni a los expedientes sancionadores sin conexión directa con los que sean objeto de las eventuales actuaciones jurisdiccionales del orden penal. Así, el Ministerio Fiscal debe notificar a la autoridad laboral y a la Inspección de Trabajo la existencia de cualquier tipo de procedimiento penal existente sobre los hechos que puedan ser constitutivos de infracción. Consecuencia de la notificación del Ministerio Fiscal, se producirá la paralización de procedimiento hasta el momento en que el propio Ministerio Fiscal notifique a la autoridad laboral la firmeza de la sentencia o auto de sobreseimiento dictado por la autoridad judicial. Consecuencia de lo dicho deducimos una clara preferencia de la imposición de sanción penal sobre la sanción administrativa, así como una más que evidente primacía de orden jurisdiccional penal sobre la propia actuación administrativa; pero esto último posee una importantísima consecuencia en el orden jurisdiccional social: la preferente posición de la estimación de los hechos objeto de debate que se hayan estipulado en el orden penal (García y Rodríguez, 2015: 487). Sin perjuicio de lo anterior, la responsabilidad administrativa sí es compatible con la responsabilidad civil y con la responsabilidad de Seguridad Social. No así con la responsabilidad penal cuando el sujeto, hecho y fundamento ponga de manifiesto la incompatibilidad entre la responsabilidad administrativa y la responsabilidad penal.

\subsection{Responsabilidad penal}

La responsabilidad penal es de naturaleza pública, posee carácter de derecho sancionador, siendo su propósito la represión pública de las conductas punibles con finalidad de carácter disuasorio y de prevención general (Pérez, 2020: 9). En el Código Penal localizamos varios preceptos que se refieren a diversos tipos penales en los que el empresario puede incurrir por transgredir su deber de protección de la seguridad y salud laboral. Dicha exigencia de responsabilidad penal se integra en la estrategia preventiva diseńada por la LPRL. Dentro del Título XV 
y que versa sobre "los delitos contra los derechos de los trabajadores", hemos de referirnos al delito doloso del artículo $316 \mathrm{CP}$, el cual, viene a confirmar que:

Los que con infracción de las normas de prevención de riesgos laborales y estando legalmente obligados, no faciliten los medios necesarios para que los trabajadores desempeñen su actividad con las medidas de seguridad e higiene adecuadas, de forma que pongan así en peligro grave su vida, salud o integridad física, serán castigados con las penas de prisión de seis meses a tres años y multa de seis a doce meses.

Como puede comprobarse del citado precepto, el objeto de tutela jurídica es la vida, salud o integridad física de los trabajadores. Y el artículo $317 \mathrm{CP}$, referido al delito culposo, establece que:

Cuando el delito a que se refiere el artículo anterior se cometa por imprudencia grave, será castigado con la pena inferior en grado.

Por tanto, no se exige resultado alguno; el artículo solo se refiere al peligro grave de la vida o salud del trabajador, por lo que nos encontramos ante un delito de riesgo y no de resultado.

Consecuentemente, el dolo no requiere la representación o aceptación de resultado lesivo; basta con el que elemento subjetivo se proyecte sobre los elementos objetivos del tipo, en este caso concreto, sobre la idoneidad peligrosa de la omisión de medios que es obligatorio facilitar (Terradillos, 2015: 523):

Y el elemento subjetivo del tipo penal que se analiza no viene representado, desde luego, por la intencionalidad de la conducta en el sentido de perseguir la causación del resultado dańoso, exigiendo el dolo únicamente la conciencia de la infracción de la norma de prevención, el conocimiento de la ausencia de facilitación de los elementos de seguridad imprescindibles y, por último, el de la existencia de una grave situación de peligro creada como consecuencia de aquellas dos omisiones (Audiencia Provincial de Madrid 13 de mayo de 2013 [ARP 2013, 1087]).

En suma es preciso analizar todos y cada uno de los elementos de seguridad existentes en la empresa para concluir si se observa una insuficiencia o defectuosidad en las medidas, es decir:

Si en general, la empresa cumplía con todas las medidas de seguridad exigidas en la construcción pero su aplicación fue defectuosa, en cuyo caso la conducta sería incardinable en el tipo imprudente, es decir, en el artículo $317 \mathrm{CP}$, o si, por el contrario, se observa en la conducta del acusado una conciencia y voluntariedad del peligro, siquiera de manera eventual en cuyo caso la conducta es incardinable en el tipo doloso previsto en el artículo 316 CP (Audiencia Provincial de Guadalajara 11 de diciembre de 2013 [ARP 2013, 1488]). 
Naturalmente, para la integración del tipo se exige que, con infracción de aquellas normas de cuidado y la omisión del cumplimiento del deber de facilitar los medios necesarios, se ponga en peligro grave la vida, la salud o la integridad física de los trabajadores sin que sea preciso que el peligro se concrete en una lesión efectiva, puesto que el delito en cuestión lo es únicamente de riesgo. Se trata de un tipo con varios elementos normativos, esto exige, para la adecuada integración del mismo, tener en cuenta lo dispuesto fuera de la norma legal, en especial, la LPRL. Es un tipo de omisión en cuanto supone el incumplimiento de las normas de cuidado expresamente establecidas en la legislación laboral (STS 12 de noviembre de 1998 [RJ 1998, 7764]). Se trata de un tipo penal de estructura omisiva más propiamente de infracción de un deber que protege la seguridad en el trabajo entendido como la ausencia de riesgos para la vida y salud del trabajador dimanante de las condiciones materiales de la prestación del trabajo, bien jurídico autónomo y por tanto independiente de la efectiva lesión que en todo caso merecería calificación independiente, en el que el sujeto activo, los legalmente obligados, ocupan una posición semejante a la de garante (STS 29 de julio de 2002 [RJ 2002, 8826]).

Es un delito de peligro, no es necesario que el peligro se concrete en una lesión efectiva. Es, obviamente, un tipo penal en blanco, pues es la infracción de la normativa laboral la que completa el tipo, entendiendo que no bastaría cualquier infracción administrativa para dar vida al tipo penal, porque exige, en adecuado nexo de causalidad, que la norma de seguridad infringida ponga en peligro grave su vida, salud o integridad física, la que nos remite a las infracciones graves de la normativa laboral. Indudablemente, sólo tienen relevancia penal las infracciones laborales más graves, no basta para la integración del tipo penal cualquier infracción de normas de seguridad, porque esto extendería indebidamente la respuesta penal en niveles incompatibles con el principio de mínima intervención y de seguridad jurídica. La integración de este tipo penal con la normativa correspondiente de prevención de riesgos laborales sólo debe ser en relación con la infracción de los más graves preceptos, cuya omisión es capaz de generar un grave peligro. Se está en consecuencia ante la infracción de una norma de seguridad que se ha reconvertido en tipo penal por la mayor lesividad que aquella infracción conlleva para el bien jurídico de la vida, salud o integridad del colectivo de trabajadores (Sentencia de la Audiencia Provincial de Badajoz 19 de diciembre de 2019 [JUR 2020, 51547]). Asimismo, debe tenerse presente que la Administración Pública, en materia de prevención riesgos laborales, tiene las mismas obligaciones que cualquier otra empresa (artículo 14.1 LPRL), equiparando la LPRL al empresario con la Administración (Sentencia de la Audiencia Provincial de Valencia 7 de marzo de 2012 [JUR 2012, 229171]).

Referirnos también al debate sobre la compatibilidad e incompatibilidad de las prestaciones correspondientes por la incapacidad resultante del siniestro laboral y la indemnización por responsabilidad civil derivada del delito. En lo 
que se refiere a la concreta incidencia de las prestaciones de Seguridad Social en la reparación íntegra del daño causado por el accidente de trabajo, se ha indicado que además de las prestaciones públicas que procedan, también puede reclamarse al empresario culpable una indemnización por los daños y perjuicios derivados del accidente laboral, porque esta responsabilidad adicional tiene carácter complementario de las prestaciones de Seguridad Social (SSTS 30 de septiembre de 1997 [RJ 1997, 6853] y 23 de abril de 2002 [RJ 2002, 7852]).

Por tanto, de un estudio jurisprudencial, puede concluirse que para determinar los dańos y perjuicios de toda índole derivados de un accidente de trabajo deberán computarse las prestaciones reconocidas en base a la normativa protectora de la Seguridad Social, en especial cuando se deba determinar el importe de la indemnización derivada de los perjuicios afectantes al ámbito profesional o laboral del accidentado, excepción hecha del recargo impuesto por falta de medidas de seguridad (STS 1 de junio de 2005 [RJ 2005, 9662] y STS 2 de febrero de 1998 [RJ 1998, 3250]). Concluimos confirmando que la responsabilidad penal no es compatible con la responsabilidad administrativa. De conformidad con el artículo 3 LISOS, en los supuestos en que las infracciones pudieran ser constitutivas de ilícito penal, la Administración pasará el tanto de culpa al órgano judicial competente o al Ministerio Fiscal y se abstendrá de seguir el procedimiento sancionador mientras la autoridad judicial no dicte sentencia firme o resolución que ponga fin al procedimiento o mientras el Ministerio Fiscal no comunique la improcedencia de iniciar o proseguir actuaciones. Responsabilidad penal que sí es compatible con la civil (lo que puede resolverse dentro del procesa penal o en el proceso civil), siendo compatible también con el recargo de Seguridad Social por falta de medidas de seguridad del conjunto indemnizatorio.

\subsection{Responsabilidad civil}

La responsabilidad civil se distingue de las otras responsabilidades por la naturaleza privada de la que goza y por los fines que persigue: la reparación del daño y perjuicio causado sobre la base de que nadie pueda causar daño a otro (principio neminem laedere) (Pérez, 2020: 24). Dentro de la responsabilidad civil es conveniente realizar una bifurcación entre responsabilidad civil derivada de la responsabilidad penal; y responsabilidad civil contractual.

Debe partirse del precepto que confirma que toda persona criminalmente responsable de un delito lo es también civilmente si del hecho se derivaren daños o perjuicios (artículo 116.1 CP). Dicha responsabilidad por la ejecución de un hecho descrito por la ley como delito obliga a reparar los dańos y perjuicios que se hayan podido ocasionar, lo que comprende (artículo $110 \mathrm{CP}$ ): $1 .^{\circ}$ La restitución; $2 .^{\circ} \mathrm{La}$ reparación del daño; $3 .^{\circ} \mathrm{La}$ indemnización de perjuicios materiales y mora- 
les. Dentro de la responsabilidad civil en relación a los riesgos laborales hemos de diferenciar entre la responsabilidad contractual (artículos 1101 y siguientes) y la responsabilidad extracontractual (artículo 1902 y siguientes). La responsabilidad contractual deriva de incumplimiento o cumplimiento defectuoso entre empresario y trabajador; y la responsabilidad extracontractual deriva de una conducta dolosa o negligente del sujeto infractor (Carrancho, 2010: 25). De conformidad con el artículo 1101 del Código Civil (responsabilidad contractual):

Quedan sujetos a la indemnización de los daños y perjuicios causados los que en el cumplimiento de sus obligaciones incurrieren en dolo, negligencia o morosidad, y los que de cualquier modo contravinieren al tenor de aquéllas.

Por tanto, es obvio que, si el empresario causa un daño por el incumplimiento de sus obligaciones en materia de prevención de riesgo laborales, deberá responder contractualmente de la misma. Los requisitos que deberán concurrir para la existencia de responsabilidad civil por daños son los siguientes (Farrés, 2007): 1) Existencia de daños al trabajador. 2) Acción u omisión, consistente en un incumplimiento, normalmente grave, por parte del empresario de sus obligaciones en materia de seguridad y salud en el trabajo. 3) Culpa o negligencia empresarial. 4) Relación de causalidad entre la conducta empresarial y el daño producido. Al hilo de lo anterior, el marco normativo de la responsabilidad contractual (artículo 42.1 LPRL; artículos 168.3 y 164 LGSS), que suele ser la apropiada para la siniestralidad laboral, requiere el incumplimiento empresarial de sus obligaciones de prevención (Fernández, 2015: 551). Y de conformidad con el artículo 1902 del Código Civil (responsabilidad extracontractual):

El que por acción u omisión causa daño a otro, interviniendo culpa o negligencia, está obligado a reparar el dańo causado.

Asimismo, la obligación que impone el artículo anterior es exigible no sólo por los actos u omisiones propios, sino por los de aquellas personas de quienes se debe responder, siendo igualmente responsables los:

Dueńos o directores de un establecimiento o empresa respecto de los perjuicios causados por sus dependientes en el servicio de los ramos en que los tuvieran empleados, o con ocasión de sus funciones (artículo 1903 Código Civil).

Teniendo en cuenta que el que paga el daño causado por sus dependientes puede repetir de éstos lo que hubiese satisfecho (artículo 1904 Código Civil). Sería la denominada responsabilidad directa y no subsidiaria de empresario por ser el centro de imputación del riesgo inherente a la actividad empresarial (García, 2006: 591). 
Analizada la normativa, jurisprudencialmente es regla general aquella que viene a recoger que el trabajador accidentado o sus causahabientes tienen derecho:

A su reparación integra, así como que las consecuencias dañosas de los accidentes del trabajo no afectan solo al ámbito laboral y a la merma de capacidad de tal naturaleza que pueda sufrir el trabajador accidentado, sino que pueden repercutir perjudicialmente en múltiples aspectos o facetas de su vida personal, familiar o social, proclamándose que los perjudicados no deben enriquecerse injustamente percibiendo indemnizaciones por encima del límite racional de la compensación plena, concluyendo así la necesidad de que todas las indemnizaciones reconocidas a favor del trabajador en las distintas vías jurisdiccionales han de ser estimadas formando parte de un total indemnizatorio (STS 23 de abril de 2009 [RJ 2009, 4140]).

Siguiendo esas pautas, cabe afirmar que las prestaciones del sistema de la Seguridad Social previstas para las contingencias profesionales no agotan todas las posibilidades de indemnizar los daños y perjuicios que ocasionen:

Las prestaciones de Seguridad Social no agotan la indemnización total que pudiera proceder en concepto de responsabilidad civil por culpa o negligencia del empresario en la producción de un accidente de trabajo, pero se integran en ese total indemnizatorio y son, por lo tanto, deducibles del importe que hubiera tenido que abonarse si no hubieran existido tales prestaciones, ya que las mismas no alteran ese importe total y no pueden adicionarse al mismo porque se produciría un exceso carente de causa (STS 9 de febrero de 2005 [RJ 2005, 6358]).

Son principios generales del Tribunal Supremo sobre la materia de responsabilidad empresarial por accidente de trabajo los siguientes. Para empezar, la doctrina es unánime a la hora de mantener el derecho a la reparación íntegra, porque como manifestación del principio general de nuestro ordenamiento jurídico (lo que se deduce de los artículos 1101 y 1902 del Código Civil) en principio la indemnización procedente deberá ser adecuada, proporcionada y suficiente para alcanzar a reparar o compensar plenamente todos los daños y perjuicios (daño emergente, lucro cesante, daños materiales y morales), que como derivados del accidente de trabajo se acrediten sufridos en las esferas personal, laboral, familiar y social (SSTS 17 de febrero de 1999 [RJ 1999, 2598] y 24 de julio de 2006 [RJ 2006, 7312]). Asimismo, el Tribunal Supremo sostiene que del referido principio de reparación íntegra se deduce la exigencia de proporcionalidad entre el daño y la reparación; y, a sensu contrario, que la reparación no debe exceder del dańo o perjuicio sufrido; dicho de otro modo, que los dańados o perjudicados no deben enriquecerse injustamente percibiendo indemnizaciones por encima del límite racional de una compensación plena (STS 17 de julio de 2007 [RJ 2007, 8300]).

Y dentro de las evidentes dificultades que supone fijar una cuantía en concepto de indemnización, con carácter general se ha mantenido que debe hacerse teniendo en cuenta la naturaleza de los hechos, el grado de culpabilidad, la de- 
pendencia económica, las sumas ya percibidas y los criterios legales que pueden servir de referencia (STS 02 de febrero de 1998 [RJ 1998, 3250] y STS 17 de febrero de 1999 [RJ 1999, 2598]). Más concretamente, a falta de norma legal expresa en materia laboral, la indemnización alcanzará sin limitación, en principio, a los daños y perjuicios que como derivados del accidente de trabajo se acrediten, aunque los órganos judiciales puedan acudir analógicamente a otras normas del ordenamiento jurídico que ante determinadas secuelas o dańos establezcan unos módulos indemnizatorios (STS 17 de julio de 2007 [RJ 2007, 8300]). Sin perjuicio de lo anterior, para la determinación de la indemnización debe tenerse en cuenta la concurrencia de culpas entre el trabajador y el empresario por incumplimiento mutuo de sus respectivas obligaciones en materia de prevención de riesgos laborales. Cuando se produce esta concurrencia de culpas, de forma que las dos actuaciones (la del empresario y la del trabajador) determinan la producción del resultado fatal, no cabe exonerar de responsabilidad al empresario, sino que, a partir de una generalización de la regla del artículo 1103 del Código Civil, hay que ponderar las responsabilidades concurrentes moderando en función de ello la indemnización a cargo del agente externo (STS 21 de marzo de 2000 [RJ 2000, 2023], STS 21 de febrero de 2002 [RJ 2002, 4539] y STS 17 de julio de 2008 [RJ 2008, 4483]). En este sentido, la imprudencia profesional o exceso de confianza en la ejecución del trabajo no tiene, cuando no opera como causa exclusiva del accidente, entidad suficiente para excluir totalmente o alterar la imputación de la infracción a la empresa, que es la que está obligada a garantizar a sus trabajadores una protección eficaz en materia de seguridad e higiene en el trabajo; siendo de resaltar que incluso la propia LPRL dispone que la efectividad de las medidas preventivas deberá prever la distracción o imprudencia temerarias que pudiera cometer el trabajador (STS 12 de julio de 2007 [RJ 2007, 8226] y STSJ de Castilla-La Mancha 17 de abril de 2012 [AS 2012, 1569]).

En definitiva, nos encontramos ante una responsabilidad por culpa, pero muy «subjetivada». La amplitud del deber de prevención del artículo 14 LPRL, así como su desarrollo reglamentario, los deberes de previsión y evaluación, la propia prevención o vigilancia, entre otros factores, han tenido la consecuencia de que el empresario se exonere de responsabilidad solo en los supuestos en los que estemos ante casos imprevisibles e inevitables del artículo 1105 del Código Civil:

Fuera de los casos expresamente mencionados en la ley, y de los en que así lo declare la obligación, nadie responderá de aquellos sucesos que no hubieran podido preverse, o que, previstos, fueran inevitables.

En suma, la exoneración de responsabilidad solo es posible cuando se prueba el cumplimiento de la diligencia debida, la existencia de una imposibilidad sobrevenida, el caso fortuito o la fuerza mayor (Fernández, 2015: 552). Res- 
pecto a la indemnización económica, nos encontramos ante una indemnización de responsabilidad por culpa lo que permitiría una reparación integral del daño pudiéndose reclamar todos los daños sufridos (daño emergente), las ganancias que se hayan dejado de obtener (lucro cesante), así como todos los daños derivados del siniestro laboral: sufrimiento físico, daño moral, disminución de la capacidad, etcétera (STS 17 de febrero de 1999 [RJ 1999, 2598] y STS 24 de julio de 2006 [RJ 2006, 7312]). Para la cuantificación de la indemnización económica habrá que estar a los criterios civilistas en los que se tendrán en cuenta la culpabilidad, la buena fe, la negligencia y el dolo. Incluso habrá que analizarse si ha existido compensación de culpa entre empresario y trabajador: normalmente, la imprudencia profesional no suele exonerar la responsabilidad de ambos; la imprudencia temeraria del trabajador sí suele exonerar de responsabilidad al empresario (Fernández, 2015: 558). Por otro lado, sin perjuicio de todo lo anterior, como ya hemos manifestado anteriormente, actualmente la LRJS, otorgando la competencia al orden jurisdiccional social, ha puesto punto y final a la dualidad jurisdiccional existente en la materia.

\subsection{Responsabilidad en Seguridad Social: el recargo de prestaciones}

Por último, la responsabilidad por incumplimientos en materia de prevención de riesgos laborales se cierra con la responsabilidad de Seguridad Social en aquellos supuestos en los que, además de un incumplimiento, se haya materializado un resultado dañoso. En efecto, la producción del resultado dañoso es la característica propia de la responsabilidad de Seguridad Social (a diferencia de la responsabilidad administrativa en la que se exigía un mero incumplimiento sin que fuera necesario el daño concreto por ser una infracción de riesgo y no de resultado). Por tanto, se exige que el trabajador haya tenido un accidente por falta de medidas de seguridad (Pérez, 2020: 27). Sin perjuicio de lo anterior, destacar que el recargo de prestaciones no es la única manifestación de esta responsabilidad (aunque será a la única que nos referiremos) (García, 2003: 154). Centrándonos en el recargo de prestaciones (Monereo, 2020: 677), hemos de situarnos en el artículo 164 LGSS. Precepto de gran rigor y concisión técnica que viene a delimitar, en sus tres apartados, el concepto y los elementos constitutivos de la institución, la naturaleza de la responsabilidad y los sujetos responsables y, por último, su carácter independiente y compatible con todo ámbito de responsabilidad, pues no vulnera el principio non bis in idem, puesto que contempla el hecho punible desde perspectivas y finalidades específicamente distintas a las sanciones administrativas (Monereo, 2015: 566). En efecto, la posible coexistencia del recargo con una sanción administrativa no comportaría vulneración del principio «non bis in ídem», pues conforme a la jurisprudencia constitucional, la regla non bis in idem no siempre imposibilita la sanción de unos mismos hechos por autoridades de distinto orden y que los contemplen, por ello, desde perspectivas diferentes (v.gr., como ilícito penal y como infracción administra- 
tiva o laboral) y que por su misma naturaleza sólo podrá invocarse en el caso de duplicidad de sanciones, frente al intento de sancionar de nuevo, desde la misma perspectiva de defensa social, unos hechos ya sancionados, o como medio para obtener la anulación de la sanción posterior, destacándose doctrinalmente que:

Es indudable que recargo de prestaciones y sanción administrativa no contemplan el hecho desde la misma perspectiva de defensa social, pues mientras el recargo crea una relación indemnizatoria empresario-perjudicado, la sanción administrativa se incardina en la potestad estatal de imponer la protección a los trabajadores (STS 2 de octubre de 2000 [RJ 2000, 9673] y STC 159/1985, de 25 de noviembre [RTC $1985,159])$.

En el recargo nos encontramos ante un componente sancionador y un componente reparador: se propone la sanción cuando el accidente haya sido consecuencia de la falta de medidas aumentando la prestación que corresponda entre un 30 y un 50\% (artículo 164 LGSS). Dicha naturaleza viene a definir el recargo como "sanción compleja unitaria de carácter intimidatorio" (Monereo, 1992: 606). Debe tenerse en cuenta que la sanción no tiene una función únicamente represiva o intimidatoria, sino también reparadora (en forma indemnizatoria) que se traduce en el aumento de la prestación para el trabajador o sus causahabientes. Especificidad de esta figura jurídica que reside, precisamente, en que no pueden separarse ambos componentes, puesto que el recargo es tanto sanción para empresario (de carácter represivo) como en indemnización para el trabajador (por su naturaleza reparadora), derivando de esas dos características el carácter sui generis del recargo (Monereo, 1992: 606; Pérez, 2020: 30). Con el citado precepto se pretende incrementar los esfuerzos de prevención de los empresarios mediante la representación de una amenaza de agravamiento de la responsabilidad patrimonial directa. La finalidad última es el reforzamiento de las normas y medidas de prevención de riesgos profesionales: estimular los esfuerzos de prevención mediante la intimidación que provoca la sanción en el posible sujeto receptor.

Para la imputación del recargo se requiere la existencia de culpa o negligencia, lo que se traduce en una responsabilidad "cuasi-objetiva», puesto que, una vez reconocida la relación de causalidad entre el accidente producido y la falta de medidas de seguridad, se entenderá que hay culpabilidad, reconociéndose la culpabilidad a modo de presunción legal de su existencia, en el momento en el que opera la relación de causalidad (Monereo, 1992: 28). Como ya hemos indicado, la responsabilidad del recargo de prestaciones es independiente y compatible con los demás ámbitos de responsabilidad que puedan derivarse del incumplimiento empresarial del deber objetivo de cuidado (Monereo, 2015: 566). Por tanto, es compatible con otras responsabilidades, como la administrativa o penal, justificándose que no se vulnere el principio non bis in ídem. Lo que se confirma por la propia norma que reconoce su compatibilidad con el resto de responsabilidades derivadas del ilí- 
cito. No obstante lo anterior, se hace preciso resaltar que, en el caso de existir responsabilidad civil por los dańos derivados y perjuicios causados, el juez de lo civil modulará la cuantía de la indemnización teniendo en cuenta el recargo impuesto (Monereo, 1992: 78; Montoya, 2004: 312).

\section{La responsabilidad empresarial en época de pandemia y crisis sanitaria en relación con la prevención de riesgos laborales}

La responsabilidad administrativa es uno de los principales mecanismos con el que exigir la garantía de cumplimiento de la legislación sobre prevención de riesgos laborales. Nos encontramos ante una responsabilidad pública dónde la administración laboral se convierte en elemento principal, tanto en la imposición de sanciones como en el control de los hechos (a través de la ITSS). Lo anterior, sin perjuicio de que las decisiones puedan ser revisadas en vía jurisdiccional. Al ser una responsabilidad de naturaleza pública, la misma debe atenerse a los principios del artículo $35 \mathrm{CE}$ : legalidad, tipicidad y non bis in idem. Este último impidiendo la imposición de dos sanciones por unos mismos hechos, así como la concurrencia de sanciones administrativas y penales en ese mismo supuesto. Además, la sanción deberá estar influenciada por el principio de proporcionalidad e imputabilidad propios de cualquier sanción. Responsabilidad administrativa cuya consecuencia suele ser, generalmente, la imposición de una multa cuya cuantía varía dependiendo de la gravedad de la infracción y que es compatible con la responsabilidad civil o patrimonial, así como con la responsabilidad de seguridad social (recargo de prestaciones) (García y Rodríguez, 2015: 489).

En relación al coronavirus (se recomienda ver el criterio técnico 103/2020 de la ITSS; criterio no vinculante en vía judicial), debe partirse de que nos encontramos ante una epidemia desconocida, con altas dosis de contagio, por lo que deben adaptarse elevadas medidas de seguridad. Además, nos situamos en un contexto de fuerza mayor, por lo que las empresas solo podrán evaluar los riesgos existentes en el entorno laboral y seguir aquellas recomendaciones que hayan sido indicadas por los servicios de prevención y autoridades sanitarias. Para analizar la responsabilidad empresarial de estos supuestos, es necesario diferenciar aquellas empresas que forman parte de ámbito de aplicación del Real Decreto 664/1997, de 12 de mayo, sobre la protección de los trabajadores contra los riesgos relacionados con la exposición a agentes biológicos durante el trabajo, de aquellas otras empresas a las que dicha normativa no le es de aplicación. A las empresas a las que le es de aplicación esta normativa, el riesgo de exposición al coronavirus sí ha de considerarse como un riesgo laboral en la medida en que la propia naturaleza de la actividad que el trabajador viene desarrollando entraña de por sí un riesgo (Domingo, Peñalosa y Salvador, 2020). Por tanto, de existir algún tipo de incumplimiento de conformidad con lo dispuesto en la 
normativa, la autoridad laboral podrá aplicar la potestad sancionadora conferida por la LPRL y por la Ley 23/2015, de 21 de julio, Ordenadora del Sistema de Inspección de Trabajo y Seguridad Social. A las empresas a las que no se le aplica la citada normativa, el riesgo de contagio no deriva de la propia naturaleza de la actividad desempeñada, sino de un factor externo. Sin perjuicio de lo anterior, estas empresas sí deberán seguir las recomendaciones y orientaciones que la autoridad sanitaria hubiera publicado habiéndose introducido las mismas en el sistema de protección de las medidas de higiene y prevención necesarias (guantes, mascarillas, distancias mínimas, aforo máximo, etcétera). Es por ello que, de conformidad con el artículo 16 LPRL, habrá de realizarse un plan de prevención de riesgos laborales, evaluación de los riesgos y planificación de la actividad preventiva con la finalidad de cumplir con el derecho a la protección frente a los riesgos laborales. Por tanto, aquellas empresas que vengan a incumplir la normativa preventiva, así como las medidas y recomendaciones necesarias podrán ser sancionadas de conformidad con el artículo 12.16 LISOS.

Por otro lado, dejando atrás la responsabilidad administrativa, la conducta de omisión e inobservancia de la normativa de prevención de riesgos laborales también puede derivar en responsabilidad penal del empresario de conformidad con los artículos 316 y 317 del Código Penal. Como ya hemos comentado, nos encontramos ante un delito de peligro que, en este caso, se concretaría en la no facilitación de los medios necesarios a los trabajadores para desempeñar su actividad con las medidas de seguridad e higiene adecuadas que eviten el riesgo de contagio o transmisión del Covid-19. Al hilo de lo anterior, se requiere no cualquier infracción administrativa, sino que la conducta omisiva cometa una infracción laboral de las más graves que impliquen la creación o admisión de un riesgo grave para la vida, salud o integridad física del trabajador; se requiere, por tanto, de un nexo de causalidad entre la norma de seguridad que se infringe y el riesgo ocasionado (Domingo, Peńalosa y Salvador, 2020).

Trasladándonos al caso concreto de crisis sanitaria, creemos que también se podrá exigir responsabilidad a una empresa cuyo sector de la actividad no estaba expuesta a riesgos biológicos pero que, tras la aparición del virus, han pasado a exponerse a un alto riesgo de contagio. Podríamos deducir que serían todas las empresas cuyas actividades, una vez declarado el estado de alarma, continuaron desarrollando servicios (especialmente, porque la normativa lo permitía: supermercados, farmacias, mercancías, etcétera). En estos casos, será fundamental que el empresario cumpla estrictamente con la normativa de prevención de riesgos laborales, así como las medidas y recomendaciones que se han ido desarrollando a lo largo de la situación de crisis. Tendrá el empresario que realizar una evaluación de riesgos y prevención, así como facilitar los medios a sus trabajadores; de lo contrario, podría incurrir en un delito contra la seguridad y salud de los trabajadores por conducta omisiva a la que se le exige dolo o imprudencia grave en su actuar. Además, en el caso de que el empresario haya decidido continuar con 
la actividad empresarial y no haya podido habilitar a sus trabajadores de los elementos de protección comunes consecuencia de la escasez y dificultades que han existido en el mercado para dicho abastecimiento, debe tenerse en cuenta que el empresario también podrá incurrir en los delitos previstos en los artículos 316 y 317 del Código Penal. No obstante lo anterior, los esfuerzos del empresario que puedan ser acreditados y que evidencien que se ha intentado, por todos los medios posibles, la adquisición del material necesario para el desarrollo de la actividad, podrán ser razones de peso para exonerar o, al menor, reducir la responsabilidad penal del empresario.

Al hilo de lo anterior, puede concluirse que la falta de adopción de medidas necesarias de seguridad y salud para evitar el riesgo o contagio del virus sí se considerará delictiva siempre que haya supuesto un riesgo grave a la vida, salud o integridad física del trabajador (aunque no se haya llegado a producir el contagio). Sin perjuicio de lo anterior, si además de dicha situación de riesgo grave se produce un efectivo daño al trabajador, al empresario también se le podría imponer un castigo de resultado producido. En este supuesto tendremos que diferenciar dos casos: a) Si se produce un contagio que exija tratamiento médico (más allá de la vigilancia o seguimiento), el empresario podría ser imputado por la comisión de un delito de lesiones por imprudencia grave (artículo 152.1 CP) o por imprudencia menos graves (artículo 152.2 CP). b) Si el contagio provoca el fallecimiento del trabajador, al empresario se le podría llegar a imputar la comisión de un delito de homicidio por imprudencia grave (artículo 142.1 CP). En tales supuestos el empresario estará obligado a asumir la responsabilidad civil derivada del pago de la indemnización correspondiente por los daños y perjuicios ocasionados. A estos efectos, es importante que, en caso de que se hayan tomado medidas preventivas por parte del empresario, analizar, caso por caso, si las mismas han sido o no suficientes para evitar el reproche penal. En estos casos, reiteramos, habrá que estar al caso concreto y analizar todos los factores concurrentes (Garrigues).

En la práctica judicial será bastante complicado demostrar la relación de causalidad entre el contagio del Covid-19 y la conducta dolosa o imprudente de la infracción de las normas de prevención de riesgos laborales. Destacar que las posibilidades de éxito de la acción ejercitada por el trabajador se verán multiplicadas cuando exista acta de infracción de la Inspección de Trabajo y Seguridad Social en el que se constate el incumplimiento de la empresa.

Todo lo anterior, teniendo en cuenta también la posibilidad de la acción de responsabilidad civil por indemnización de los daños y perjuicios que el trabajador haya podido sufrir a consecuencia del contagio lo que, obviamente, también entrañará problemas en la prueba de la relación de causalidad. Responsabilidad civil que tendrá que ventilarse en la jurisdicción social utilizándose para ello el baremo de lesionados destinado a los accidentes de tráfico. 
Además, es importante traer a colación la carga de la prueba de conformidad con el artículo 96 LRJS:

En los procesos sobre responsabilidades derivadas de accidentes de trabajo y enfermedades profesionales corresponderá a los deudores de seguridad y a los concurrentes en la producción del resultado lesivo probar la adopción de las medidas necesarias para prevenir o evitar el riesgo, así como cualquier factor excluyente o minorador de su responsabilidad. No podrá apreciarse como elemento exonerador de la responsabilidad la culpa no temeraria del trabajador ni la que responda al ejercicio habitual del trabajo o a la confianza que éste inspira.

Por tanto, recaerá en la empresa la obligación de probar que la misma adoptó todas las medidas necesarias para prevenir el riesgo de contagio. E incluso la empresa responderá, aunque exista culpa no temeraria del trabajador.

Como recapitulación, el trabajador contagiado por Covid-19 tiene un amplio abanico de posibilidades para exigir y reclamar la reparación del daño sufrido al empresario, aunque, como viene siendo habitual, tendremos que esperar y atender a los primeros pronunciamientos judiciales con los que podremos observar que tipo de interpretación (amplia o restrictiva) se realiza respecto a las posibles responsabilidades generadas.

\section{Bibliografía}

Alegre Nueno, M. (2019) «La participación de los delegados de prevención en el sistema de gestión de los riesgos laborales», en Gestión Práctica de Riesgos Laborales: Integración y Desarrollo de la Gestión de la Prevención, núm. 175.

Carrancho Herrero, M. T. (2010) Responsabilidad civil del empresario en el ámbito de los riesgos laborales, Madrid, La Ley.

Domingo Monforte, J., Peñalosa, C. y Salvador, N. (2020) «Responsabilidad empresarial por contagio", en Diario La Ley, núm. 9631, Sección Tribuna, 13 de mayo, Wolters Kluwer. Publicado también en Web Domingo Monforte Abogados Asociados. Puede verse en el siguiente enlace: https:/www.domingomonforte.com/responsabilidad-empresarial-por-contagio/

Farrés MarsińaCh, X. (2007) «La responsabilidad del empresario y del trabajador en materia de prevención de riesgos laborales», en Noticias Jurídicas.

Fernández Avilés, J. A. (2015) «Responsabilidades civiles», en AA. VV.: Tratado de prevención de riesgos laborales. Teoría y práctica, Madrid, Tecnos.

Fernández Bernat, J. A. (2014) Infracciones y sanciones en materia de prevención de riesgos laborales: la responsabilidad administrativa del empresario, Granada, Comares.

García González, G. (2020) «Las responsabilidades de los auxiliares del empresario en la prevención de los riesgos profesionales: déficits normativos e integraciones jurisprudenciales", en AA. VV.: Accidentes de trabajo y enfermedades profesionales. Experiencias y desafios de una protección social centenaria. IV Congreso Internacional y XVII Congreso Nacional de la Asociación Española de Salud y Seguridad Social, Tomo I, Murcia, Laborum. 
García Miguélez, M. P. (2009) «La participación de los trabajadores en materia de prevención de riesgos laborales», en Pecvnia, núm. 8.

García Murcia, J. (2003) Responsabilidades y sanciones en materia de seguridad y salud en el trabajo, Pamplona, Aranzadi.

García Murcia, J. (2006) «El TRLISOS en relación con otros órdenes sancionadores en materia de prevención de riesgos laborales: responsabilidad penal, responsabilidad de Seguridad Social y responsabilidad civil», en AA. VV.: Comentario sistemático al Texto Refundido de la Ley de Infracciones y Sanciones en el Orden Social y normas concordantes, Granada, Comares.

García Murcia, J. y Rodríguez Cardo, I. A. (2015) «Responsabilidades administrativas laborales", en AA. VV.: Tratado de prevención de riesgos laborales. Teoría y práctica, Madrid, Tecnos.

GARRIGUes, Web: https://www.garrigues.com/es_ES/noticia/covid-19-el-mantenimientode-la-actividad-productiva-puede-generar-un-potencial-problema

Guindo Morales, S. (2020) «Medidas sociolaborales de prevención de riesgos tras la pandemia ocasionada por el SARS-COV-2 contenidas en el derecho de emergencia», en AA. VV.: Accidentes de trabajo y enfermedades profesionales. Experiencias y desafios de una protección social centenaria. IV Congreso Internacional y XVII Congreso Nacional de la Asociación Española de Salud y Seguridad Social, Tomo II, Murcia, Laborum.

Mercader Uguina, J. R. (2020) «El sistema de responsabilidad empresarial por el accidente de trabajo: un modelo de transición", en AA. VV.: Accidentes de trabajo y enfermedades profesionales. Experiencias y desafios de una protección social centenaria. IV Congreso Internacional y XVII Congreso Nacional de la Asociación Española de Salud y Seguridad Social, Tomo I, Murcia, Laborum.

Montoya Melgar, A. (2004) «El panorama de las responsabilidades del empresario en materia de seguridad y salud en el trabajo», en Revista del Ministerio de Trabajo y Asuntos Sociales, núm. 53.

Monereo Pérez, J. L. (1992) El recargo de prestaciones por incumplimiento de medidas de seguridad e higiene en el trabajo, Madrid, Civitas.

Monereo Pérez, J. L. (2015) «El recargo de prestaciones como supuesto especial de responsabilidad», en AA. VV.: Tratado de prevención de riesgos laborales. Teoría y práctica, Madrid, Tecnos.

Monereo Pérez, J. L. (2017) «Derechos a la información y consulta», en Monereo Atienza, C. y Monereo Pérez, J. L. (Dirs. y Coords.) et al: La garantía multinivel de los Derechos Fundamentales en el Consejo de Europa, Granada, Comares.

Monereo Pérez, J. L. (2017) La metamorfosis del derecho del trabajo, Albacete, Bomarzo.

Monereo Pérez, J. L. (2020) «El recargo de prestaciones a la prueba de los desafíos de la «sociedad del riesgom", en AA. VV.: Accidentes de trabajo y enfermedades profesionales. Experiencias y desafios de una protección social centenaria. IV Congreso Internacional y XVII Congreso Nacional de la Asociación Española de Salud y Seguridad Social, Tomo I, Murcia, Laborum.

Monereo Pérez, J. L. y López Insua, B. M. (2015) «La política del derecho de la prevención de riesgos laborales en las empresas", Revista derecho del trabajo, núm. 8.

Monereo Pérez, J. L. y López Insua, B. M. (2016) «El derecho a la prevención: un análisis del modelo organizativo preventivo español», en Estudios financieros, núm. 395.

Monereo Pérez, J. L. y Moreno Vida, M. N. (2018) «La Directiva Marco 89/391/CEE como eje del Derecho social comunitario de la prevención de riesgos laborales», en AA. VV.: Derecho Social de la Unión Europea: aplicación por el Tribunal de Justicia, Madrid, Francis Lefebvre. 
Monereo Pérez, J. L. y Ortega Lozano, P. G. (2020) «Derecho de información [Art. 20.1) CE y normas concordantes]", en AA. VV.: Derechos laborales fundamentales inespecificos, Granada, Comares.

Ortega Lozano, P. G. (2020) «La delimitación de la responsabilidad del empresario y del trabajador en materia de prevención de riesgos laborales», en AA. VV.: Accidentes de trabajo y enfermedades profesionales. Experiencias y desafíos de una protección social centenaria. IV Congreso Internacional y XVII Congreso Nacional de la Asociación Española de Salud y Seguridad Social, Tomo I, Murcia, Laborum.

Ortega Lozano, P. G. y Guindo Morales, S. (2020) «Las diversas posibilidades de indemnización por resarcimiento en la sanidad pública española: responsabilidad objetiva, nexo causal, «lex artis» y resultado producido., en Nueva revista española de derecho del trabajo, núm. 228.

Payá Castilblanque, R. y Beneyto Calatayud, P. J. (2018) «Participación sindical y salud laboral. Una relación positiva», en Barataria: Revista Castellano-Manchega de Ciencias Sociales, núm. 24.

Payá Castilblanque, R. y Beneyto Calatayud, P. J. (2019) «Integración de la salud laboral con medios propios como mecanismo de participación y activación cultural», en Archivos de Prevención de Riesgos Laborales, núm. 22 (2).

Pérez Hernández, M. ${ }^{a}$. M. (2020) La responsabilidad administrativa de empresario en prevención de riesgos laborales, Granada, Comares.

Terradillos Basoco, J. M. ${ }^{a}$. (2015) «Responsabilidades penales», en AA. VV.: Tratado de prevención de riesgos laborales. Teoría y práctica, Madrid, Tecnos.

ValdeOlivas García, Y. (2012) Aseguramiento y protección social de los riesgos profesionales. Análisis a la luz de la responsabilidad empresarial en materia preventiva, Albacete, Bomarzo. 